locomotor organ, and then has to cheat a good deal to fill the pages. There are problems of demarcation, with discussions of skull mobility in birds and reptiles occurring both here and in volume two, and the protrusile mechanisms of fish jaws in neither.

It is a remarkable achievement on the part of the editors to have brought out all three volumes simultaneously, so perhaps we should not complain too much about uneven coverage and poor coordination between chapters. Many of us will be glad to possess this work, but it will not always tell us what we hope to learn from it.

R. McNeill Alexander is in the Department of Pure and Applied Biology, University of Leeds, Leeds LS2 9JT, UK

\section{Criminal portraits}

\section{Chris Brand}

The Psychology of Crime. By Philip Feldman. Cambridge University Press: 1993. Pp. 526. £37.50, \$64.95 (hbk); £15.95, $\$ 19.95$ (pbk).

OSTENSIBLY, criminality presents an easy target for psychology. Crimes are relatively objective social facts - not conjured up by experts, but reported mainly by members of the public and, when serious, tried by socially representative juries. Crime has a highly skewed distribution: more than fifty per cent of crimes are committed by less than five per cent of the population. Ninety-five per cent of crimes involve males aged between 14 and 40 . Crime rates show big group differences, with Japan and Switzerland the safest countries; and crime has increased enormously since 1950 in parallel with rising affluence and the number of criminologists. Yet, as Feldman's textbook faithfully records, from American and British work, there is little agreement about the psychology of crime.

To be sure, the once radical ideas of criminals as victims of loveless homes, poverty and 'labelling' can now largely be set aside. Most of the siblings of criminals have no convictions; self-reported delinquency bears no relationship to social class in modern studies; and police "targetting' of Black youths barely exceeds the reasonable requirements of economy in the use of manpower. Feldman proceeds fairly and factually to reprove oncefashionable Marxist notions of crime as a form of class war: for crime is as much a scourge of municipal housing estates as it is of leafy garden suburbs; and criminals, victims and the police show excellent agreement about the gravity of crimes and their proper punishment.

Nor has positive explanatory progress been lacking. While social-environmental accounts of crime remain popular only with tenured sociologists, the psychogenetic methods of twin studies have repeatedly shown a substantial involvement of genetic factors, as well as a minor but clearly detectable involvement of geneticenvironment interaction. The problem, however, is to say what exactly is inherited, and which variables 'interact' with each other.

Feldman summarizes some of the modern evidence linking criminality to enduring characteristics of early origin such as aggressiveness, impulsivity, sensationseeking, hostility, neuroticism and lack of empathy. In particular, he largely admits the evidence for the causal involvement of low IQ in criminality, enabling the startling Black-White difference in crime rates to be handled unprovocatively. Yet trait names are hardly very interesting without an accompanying theory - for example, of the kind there used to be about 'extraversion' (now linked only to delinquency and not to adult criminality) and its basis in poor attention and arousal. Although Feldman warms to the 'interactive' idea that some children are particularly hard to socialize and lack the crucial ingredient of supervision in homes where the father is an alcoholic bully and the mother a pill-swallowing hysteric, he never really commits himself to particular stories that spell matters out. His own theoretical preference is for a 'cognitivebehavioural' approach. But this involves mainly jargon-infected common sense ("stimuli associated with successful property offenses, e.g. opening car doors, will become cues for future theft behavior"); and so little modern empirical work is reported that the chapter on the approach is embarrassingly insubstantial and dated.

Feldman can hardly be blamed for the modern psychology of personality being richer in dimensions than in explanations. Yet it is strange that he will not even ponder such cases as, say, the rape, in 1992, of a hundred-year-old woman in her own bathroom by a sixteen-year-old from Great Yarmouth, England (finally sentenced to nine years in a young offenders' institution). Such cases, with their horrific mixture of sex and violence, should remind the psychologist of the elemental forces and incandescent hostility that are the essential ingredients of many criminal acts. It is not actually easy to burgle or vandalize, let alone to rape and maim, while embarked only on the well-laid schemes of self-reward specified by Feldman's favourite 'rational choice theory'. Although the authoritarian (and 'racist') views and lifelong irreligiosity of criminals are legendary, Feldman is ideologically reluctant to use emotional blunting and unintelligent tough-mindedness as the psychologist's guide in accounting for crime.
Thereby hangs another tale. For, as well as failing to highlight affectionlessness, Feldman has little to say about the crucial interaction between affectionlessness and consciencelessness (or, in some cases, alcohol consumption) that must complete any psychologist's first sketch of the crime scene. All this is strange: for most social scientists have long subscribed to the view (first put forward by Sir Cyril Burt in 1925) that crime and delinquency involve a number of variables in interaction with each other. What seems to have happened is that 'interactionism' has become a form of piety, notably sparing the faithful from the heresy of hereditarianism. Instead of looking for actual multiplier effects between the psychological and social variables known to be implicated in criminality, psychologists have settled for seeing off sociology. Too fainthearted to invoke the principal potentiating forces that Freud had called perhaps too romantically for psychologists with scientific aspirations - eros and thanatos, psychologists thus limit themselves to latter-day behaviourism. Instead of a psychology of crime, Feldman fills out his book with chapters on policing, the courts, the penal system and crime prevention. This will be useful enough to some students of crime, as will the detail on the complete failure, so far, of psychological 'therapies' for crime; but readers wanting some 'psychology' to apply to Feldman's facts and figures will have to supply it themselves.

Chris Brand is in the Department of Psychology, University of Edinburgh, George Square, Edinburgh EH8 9JZ, UK.

\section{Bird watching}

\section{SaraJ. Shettleworth}

Vision, Brain and Behaviour in Birds. Edited by Philip Zeigler and HansJoachim Bischof. MIT Press: 1993. Pp. 415. \$75, £67.50.

BIRDS are among the most visually accomplished of animals. The peacock's tail and the bowerbird's elaborately decorated bower testify to the importance of visual signals in birds' lives. Sexual selection may have even worked on some birds' ability to respond to such subtle visual features as symmetry of body pattern.

Birds are also masters of coordinating vision and movement. Consider a swallow capturing insects while flying, a heron standing on the shore and spearing underwater prey, or a gannet plunging out of the sky for fish. Even birds that feed on stationary prey, such as the granivorous pigeon, can exquisitely adjust the width of their gape to the diameter of the seed they 